\title{
The role of mother's education in the nutritional status of children in Serbia
}

\author{
Zeljka Stamenkovic ${ }^{1, *}$, Bosilika Djikanovic ${ }^{1}$, Ulrich Laaser $^{2}$ and \\ Vesna Bjegovic-Mikanovic ${ }^{1}$ \\ ${ }^{1}$ Institute of Social Medicine, Medical Faculty University of Belgrade, Dr Subotica 15, 11000 Belgrade, Serbia: \\ ${ }^{2}$ Section of International Public Health (S-IPH), Faculty of Health Sciences University of Bielefeld, Bielefeld, Germany
}

Submitted 20 October 2015: Final revision received 29 February 2016: Accepted 10 March 2016: First published online 18 April 2016

\begin{abstract}
Objective: The present study aimed to identify the role of mother's education in the nutritional status of children aged 2-5 years in Serbia.

Design: Nationally representative population-based study. Age- and gender-specific BMI percentiles of children were analysed. In accordance with the WHO growth reference, children with BMI less than the 5th percentile were considered undernourished. Logistic regression was used to calculate the association between mother's education and other socio-economic determinants as possible confounders.

Setting: UNICEF's fourth Multiple Indicator Cluster Survey, conducted in both Roma and non-Roma settlements in Serbia.

Subjects: Children ( $n$ 2603) aged $2-5$ years (mean age 3.05 years).

Results: Less than $5 \%$ of children aged 2-5 years were undernourished. There were significantly more undernourished children among the Roma population, in the capital of Serbia and among those whose mothers were less educated. There were statistically significant differences according to mother's education in all socio-economic characteristics (ethnicity, area, region of living and wealth index). Mother's level of education proved to be the most important factor for child's nutritional status; place of living (region) was also associated.

Conclusions: Mother's education is the most significant predictor of children's undernutrition. It confirms that investment in females' education will bring benefits and progress not only for women and their children, but also for society as a whole.
\end{abstract}

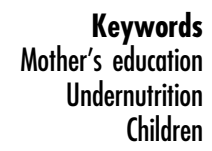

Child undernutrition is a significant global health problem and one of the leading risk factors for child mortality and morbidity worldwide ${ }^{(1)}$. It accounts for $45 \%$ of all deaths in children under the age of 5 years ${ }^{(2)}$. Since adequate nutrition is essential during childhood to ensure healthy growth, undernutrition during early childhood may substantially increase vulnerability to infection and disease and the risk of premature death ${ }^{(3)}$. Undernutrition in children leads to permanent effects diminishing health capital later in life. It produces serious health, social and economic consequences in the course of life, as well as across generations ${ }^{(3-7)}$

The child undernutrition prevalence rate remains a significant public health problem in many developing countries, including Serbia. Based on data from 2005 and 2010, undernutrition has increased in Serbia and become more alarming. Multiple Indicator Cluster Surveys (MICS) have been conducted periodically in Serbia (2010 and 2005).
These surveys showed that the prevalence of child undernutrition (under the age of 5 years) in 2010 was higher than that in 2005 in non-Roma and Roma children (11\% v. $13 \%$ for non-Roma children, $31 \% v$. $28 \%$ for Roma children) ${ }^{(8,9)}$.

To date, different studies have shown that various indicators of socio-economic status are associated with children's nutritional status, such as educational level of parents, parental income and family assets ${ }^{(10-14)}$. Poverty, which is very typical for low- and middle-income countries, is one of the main risk factors for child undernutrition. Low level of household wealth is also a background characteristic contributing to the prevalence of undernourished children ${ }^{(13,15-18)}$. While low household income has a negative effect on children's nutritional status, education acts as a protective factor following the pattern that children whose mothers have higher or high education are more likely to be well-nourished ${ }^{(12-14)}$. 
Some studies have confirmed that mother's education is one of the main determinants of undernutrition ${ }^{(12-14)}$. Also, it has been shown that children whose mother was more educated were more likely to consume the optimal amounts of protein, $\mathrm{Ca}$ and vitamins necessary for their proper physical and psychological growth ${ }^{(19)}$. Apart from the socio-economic impact on child undernutrition, some recent studies have confirmed a negative influence of health factors such as diarrhoea or symptoms of respiratory disease on children's nutritional status ${ }^{(20-22)}$.

So far, little is known about the contribution of maternal education to the occurrence of child undernutrition in Serbia, as well as the interrelatedness of other sociodemographic factors and new health symptoms. Therefore, the present study aimed to identify whether and how mother's education is associated with the nutritional status of children aged 2-5 years in Serbia.

\section{Method}

\section{Population and sampling}

The present study was performed as a secondary data analysis of the fourth Multiple Indicator Cluster Survey (MICS4) that was conducted in Serbia in 2010, carried out by the Statistical Office of the Republic of Serbia with support from $\mathrm{UNICEF}^{(9)}$.

The MICS4 was conveyed in two separate population samples: (i) a national sample representative of the population of Serbia; and (ii) a national Roma sample representative of the population living in Roma settlements in Serbia. In the present study we were interested in the population of children aged 2-5 years. MICS4 was conducted at the national level for urban and rural areas, and for four regions composing Serbia: Belgrade, Vojvodina, Sumadija and Western Serbia, and Southern and Eastern Serbia. For both populations, the following sampling method was used to ensure representativeness and random selection of households. The urban and rural domains within twenty-five areas were identified as the main sampling strata, and the sample was selected in two stages. Within each stratum, a specified number of census enumeration areas was selected systematically with probability proportional to size. After a household listing was carried out within the selected enumeration areas, the listed households were divided into households with and without children under the age of 5 years, and then a separate systematic sample of households was selected for each group.

According to this recruitment method 6885 non-Roma households were randomly selected, and 6803 were found to be occupied during the survey and approached by interviewers. In 6392 non-Roma households the interview was completed (household response rate was $94 \%$ ). In the interviewed households 3398 non-Roma children under 5 years of age were identified, and 3374 of them completed the questionnaire (response rate within interviewed households was 99\%).

According to this recruitment method 1815 Roma households were randomly selected, and 1782 were found and successfully approached by interviewers. In 1711 Roma households the interview was completed (household response rate was 96\%). In the interviewed households 1618 Roma children under 5 years of age were identified, and 1604 of them completed the questionnaire (response rate within interviewed households was 99\%).

In the present study we selected children who fulfilled the following criteria: (i) they were $2-5$ years old; and (ii) their height and weight were measured. The number of children who met these criteria and who therefore were included in the study was 2603 (1734 non-Roma and 869 Roma children).

\section{Survey instrument}

Information on sociodemographic characteristics of children was obtained from the household questionnaire (Household Questionnaire), while the information on new health symptoms that a child might have were obtained using the questionnaire for children under the age of 5 years (Questionnaire for Children Under Five). Both questionnaires were administered to mothers (or primary caregivers), filled in during a face-to-face interview conducted by trained interviewers and completed for each child up to the age of 5 years living in that household. Both questionnaires were based on the standard questionnaires that are used in MICS rounds ${ }^{(9)}$. After the questionnaires had been completed, anthropometric measurements (weight and height) were done by trained interviewers, using anthropometric equipment recommended by UNICEF. Children's weight was measured with a Seca 874 U Scale. Height was measured with a measuring board placed on a stable surface against a wall, table, tree or staircase. Children were without footwear and should have removed all but minimal clothes (such as their underwear) to obtain an accurate weight.

\section{Variables}

We were interested in three groups of variables in the present study: (i) sociodemographic characteristics of the household and mother/caregiver; (ii) the recent presence of certain health symptoms in children; and (iii) anthropometric measures that were used to calculate BMI.

Sociodemographic characteristics employed in the current analysis include: ethnicity (non-Roma/Roma); gender (male/female); type of settlement (urban/rural); region (Belgrade, Vojvodina, Sumadija and Western Serbia, and Southern and Eastern Serbia); mother's education (no school at all, primary school, secondary school and university degree); and wealth. Wealth of the household was measured by the Demographic and Health Survey Wealth Index (hereafter, 'wealth index'), which in its calculation includes variables related to examinees' 
assets (i.e. household facilities) ${ }^{(23)}$. The statistical procedure of principal components analysis was used to assign the factor scores to each variable. The resulting asset scores were standardized in relation to a standard normal distribution with a mean of 0 and an SD of 1 . These standardized scores were summed up by household and individuals were ranked according to the total score of the household. According to the wealth index, respondents were classified into five socio-economic groups or quintiles: poorest, poorer, middle, richer and richest, with the same number of individuals in each. Information related to the recent presence of certain health symptoms included symptoms of diarrhoea and cough. Mothers/ caregivers of children were supposed to answer whether their child had had diarrhoea or a cough within the last 2 weeks preceding the interview.

The outcome of interest was age- and gender-specific BMI of children aged 2-5 years, whose percentiles were constructed according to the WHO Child Growth Standards, released in April 2006 ${ }^{(24)}$. We used percentiles for assessing/indicating the relative position of the child's BMI value among children of the same gender and age. An unfavourable nutritional status for children aged $2-5$ years was determined using the cut-off for undernutrition: less than the 5 th percentile ${ }^{(25)}$.

\section{Statistical analysis}

Data were analysed by the $\chi^{2}$ test and logistic regression analyses. Chi-square analyses were used to test differences in the frequency of answers to each variable between these two samples and also to test the differences in the level of mother's education and their sociodemographic characteristics. To assess the degree of correlation between variables, the Spearman correlation coefficient was calculated.

Univariate logistic regression analysis examined the association between children's undernutrition, socioeconomic characteristics and recent health status. Multicollinearity among independent variables was tested by the test of tolerance and variance inflation factor values. All variables whose $P$ values in univariate logistic regression analysis were less than 0.05 were included in the multivariate logistic regression analysis. Three separate multivariate models were generated. The results of regression analyses were presented as odds ratios with $95 \%$ confidence intervals, and considered significant if the $P$ value was less than 0.05 .

The analyses were done using the statistical software package IBM SPSS Statistics Version 20.

\section{Results}

Out of 2603 children aged 2-5 years (mean age 3.05 years), less than $5 \%$ (116 or $4.45 \%$ ) were undernourished according to the WHO Child Growth Standard.
Data on undernourished children were stratified for a broad range of socio-economic characteristic and new symptoms of diarrhoea or a cough in the last 2 weeks (Table 1). We found statistically significant differences in the number of undernourished children in the two ethnic groups (nonRoma and Roma population), regarding the region they lived in and mother's level of education (Table 1). More than one-third of all children (37.3\%) had a cough within the 2 weeks preceding the interview. There were fewer undernourished children in the group who had a cough within the 2 weeks before the interview in comparison to those who did not have this symptom (3.5\% v. 5.0\%).

The majority of mothers of children in our sample held a secondary education ( $41.8 \%)$; less than every third women in the sample had just primary education (31.8\%) and no education at all was confirmed by $7.6 \%$ of women (Table 1). When stratifying by the level of mother's education, for all sociodemographic characteristics we found that there were statistically significant differences in the tested categories (Table 2). While $86.4 \%$ of non-Roma mothers obtained a secondary or higher/high degree, only $8.8 \%$ of Roma mothers had a secondary or higher/high level of education. On the other hand, $91.1 \%$ Roma mothers finished only primary school or had no education at all. When looking at the regional distribution of mother's (un)education (both samples together), we found that the largest percentage of mothers who had no education at all $(13.0 \%)$ lived in Southern and Eastern Serbia. This result is significantly higher than in other regions (Vojvodina, Belgrade, and Sumadija and Western Serbia) where the percentage of uneducated mothers was $8.4 \%, 4.8 \%$ and $2.0 \%$, respectively. Also, results showed that the highest percentage of mothers with higher/high level of education was found in Belgrade (24.5\%), in comparison to other regions where this percentage was significantly lower (Sumadija and Western Serbia, 21.9\%; Vojvodina, 19.3\%; Southern and Eastern Serbia, 11.6\%; Table 2).

Before conducting the univariate and multivariate logistic regression analyses, preliminary analyses which tested the assumptions of normality, linearity, multicollinearity and homogeneity of variance were done and demonstrated that they were not disturbed. The correlation coefficient between ethnicity and mother's education (0.712) showed that high correlation exists, but the value of this correlation was not high enough to conduct analyses for the Roma and non-Roma samples separately. Univariate logistic regression analysis was performed to determine the associations of socio-economic characteristics and recent health status with undernutrition (Table 3). The results indicated that Roma children were more often undernourished than non-Roma children $(\mathrm{OR}=1 \cdot 79 ; 95 \% \mathrm{CI} 1 \cdot 23,2 \cdot 60)$. In comparison to Belgrade, children who lived in all other regions had lower chance to be undernourished (Vojvodina: OR $=0.48 ; 95 \%$ CI 0.30, 0.76; Sumadija and Western Serbia: $O R=0 \cdot 22$; $95 \%$ CI 0.11, 0.42; Southern and Eastern Serbia: OR=0.40; 
Table 1 Socio-economic characteristics and recent health status, according to nutritional status, among children aged 2-5 years from Roma and non-Roma settlements; UNICEF fourth Multiple Indicator Cluster Survey, Serbia, 2010

\begin{tabular}{|c|c|c|c|c|c|c|c|}
\hline & \multicolumn{2}{|c|}{ Undernourished (n 116) } & \multicolumn{2}{|c|}{ Others ( $n$ 2487) } & \multicolumn{2}{|c|}{ Total ( $n$ 2603) } & \multirow[b]{2}{*}{$P$ value } \\
\hline & $n$ & $\%$ & $n$ & $\%$ & $n$ & $\%$ & \\
\hline \multicolumn{8}{|l|}{ Socio-economic characteristic } \\
\hline Ethnicity & & & & & & & 0.003 \\
\hline Non-Roma & 62 & $3 \cdot 6$ & 1672 & $96 \cdot 4$ & 1734 & $66 \cdot 6$ & \\
\hline Roma & 54 & $6 \cdot 2$ & 815 & $93 \cdot 8$ & 869 & 33.4 & \\
\hline Gender & & & & & & & 0.765 \\
\hline Male & 58 & $4 \cdot 3$ & 1290 & $95 \cdot 7$ & 1348 & $51 \cdot 8$ & \\
\hline Female & 58 & 4.6 & 1197 & $95 \cdot 4$ & 1255 & $48 \cdot 2$ & \\
\hline Area & & & & & & & 0.144 \\
\hline Urban & 78 & $5 \cdot 0$ & 1492 & $95 \cdot 0$ & 1570 & $60 \cdot 3$ & \\
\hline Rural & 38 & $3 \cdot 7$ & 995 & $96 \cdot 3$ & 1033 & $39 \cdot 7$ & \\
\hline Region & & & & & & & $<0.001$ \\
\hline Belgrade & 45 & $8 \cdot 6$ & 481 & 91.4 & 526 & $20 \cdot 2$ & \\
\hline Vojvodina & 33 & $4 \cdot 3$ & 741 & $95 \cdot 7$ & 774 & $29 \cdot 7$ & \\
\hline Sumadija and Western Serbia & 11 & $2 \cdot 0$ & 541 & 98.0 & 552 & $21 \cdot 2$ & \\
\hline Southern and Eastern Serbia & 27 & $3 \cdot 6$ & 724 & $96 \cdot 4$ & 751 & 28.9 & \\
\hline Mother's education & & & & & & & 0.046 \\
\hline None & 9 & 4.5 & 190 & 95.5 & 199 & $7 \cdot 6$ & \\
\hline Primary & 49 & $5 \cdot 9$ & 780 & $94 \cdot 1$ & 829 & 31.8 & \\
\hline Secondary & 45 & $4 \cdot 1$ & 1044 & 95.9 & 1089 & $41 \cdot 8$ & \\
\hline Higher/high & 13 & $2 \cdot 7$ & 473 & $97 \cdot 3$ & 486 & $18 \cdot 7$ & \\
\hline Wealth index quintile & & & & & & & 0.068 \\
\hline Poorest & 28 & $24 \cdot 1$ & 519 & $20 \cdot 9$ & 547 & $21 \cdot 0$ & \\
\hline Second & 11 & 9.5 & 488 & $19 \cdot 6$ & 499 & $19 \cdot 2$ & \\
\hline Middle & 23 & $19 \cdot 8$ & 458 & 18.4 & 481 & 18.5 & \\
\hline Fourth & 22 & $19 \cdot 0$ & 494 & $19 \cdot 9$ & 516 & $19 \cdot 8$ & \\
\hline Richest & 32 & $27 \cdot 6$ & 528 & $21 \cdot 2$ & 560 & 21.5 & \\
\hline \multicolumn{8}{|l|}{ Recent health symptoms } \\
\hline \multicolumn{8}{|l|}{ Child had diarrhoea in last 2 weeks } \\
\hline Yes & 9 & 3.9 & 221 & $96 \cdot 1$ & 230 & 8.8 & 0.801 \\
\hline No & 107 & 4.5 & 2266 & 95.5 & 2373 & $91 \cdot 2$ & \\
\hline \multicolumn{8}{|l|}{ Child had cough in last 2 weeks } \\
\hline Yes & 34 & 3.5 & 937 & $96 \cdot 5$ & 971 & $37 \cdot 3$ & 0.085 \\
\hline No & 82 & $5 \cdot 0$ & 1550 & $95 \cdot 0$ & 1632 & $62 \cdot 7$ & \\
\hline
\end{tabular}

*According to the $\chi^{2}$ test.

$95 \%$ CI $0 \cdot 24,0 \cdot 65)$. Children whose mothers had finished only primary school had more than two times greater risk to be undernourished in comparison to children whose mothers had finished higher or high school $(\mathrm{OR}=2 \cdot 29$; $95 \%$ CI 1.23, 4.26). The presence of certain health symptoms (diarrhoea or a cough) showed no association with undernutrition (Table 3).

To control for the possible impact of confounding variables in the observed associations with undernutrition, three multivariate-adjusted logistic regression analyses were undertaken (Table 4). In the first multivariate logistic regression model, which included ethnicity, wealth index and region, the role of ethnicity remained almost equally $(\mathrm{OR}=1.79)$ and significantly $(P=0.005)$ associated with undernutrition as in the univariate logistic regression analysis, as did the wealth index and region, although slightly attenuated. However, after adding mother's education in the second model, the significance of the association of undernutrition with ethnicity completely disappeared $(P=0 \cdot 162)$, but secondary education (relative to higher education) became a predictor of children's undernutrition $(\mathrm{OR}=1.92 ; 95 \% \mathrm{CI} 1.00,3.67)$. The third multivariate logistic regression model was performed after removing ethnicity, and showed stronger relationships between the primary and secondary level of mother's education and undernutrition (respectively: $\mathrm{OR}=2.98$; $95 \%$ CI 1.50, 5.94 and OR=2.02; $95 \%$ CI 1.06, 3.86).

In two out of three models, the wealth index did not change its relationship significantly. This result confirmed that only children belonging to the second poorest socioeconomic group were less likely to be undernourished in comparison to those who belonged to richest socioeconomic category (model 1: OR $=0.46$; CI 95\% 0.22, 0.94; model 2: OR=0.39; CI 95\% 0.19, 0.82). Belgrade was the region with a significantly higher proportion of undernourished children, and this association remained significant and almost unchanged even after controlling for all other independent variables in all multivariate models.

\section{Discussion}

In the present study we investigated the associations between children's undernutrition and a wide range of socio-economic determinants, based on a nationwide 
Table 3 Univariate logistic regression analysis: associations of socio-economic characteristics and recent health status with undernutrition of children aged 2-5 years from Roma and non-Roma settlements; UNICEF fourth Multiple Indicator Cluster Survey, Serbia, 2010

\begin{tabular}{|c|c|c|c|}
\hline & \multicolumn{3}{|c|}{ Univariate logistic regression } \\
\hline & $P$ value & OR & $95 \% \mathrm{Cl}$ \\
\hline \multicolumn{4}{|l|}{ Socio-economic characteristic } \\
\hline \multicolumn{4}{|l|}{ Ethnicity } \\
\hline Non-Roma & \multicolumn{3}{|c|}{1.00 (Reference) } \\
\hline Roma & 0.002 & 1.79 & $1 \cdot 23,2 \cdot 60$ \\
\hline \multicolumn{4}{|l|}{ Area } \\
\hline Urban & \multicolumn{3}{|c|}{1.00 (Reference) } \\
\hline Rural & 0.120 & 0.73 & $0.49,1.08$ \\
\hline \multicolumn{4}{|l|}{ Gender } \\
\hline Male & \multicolumn{3}{|c|}{1.00 (Reference) } \\
\hline Female & 0.694 & 1.08 & $0.74,1.56$ \\
\hline \multicolumn{4}{|l|}{ Wealth index quintile } \\
\hline Poorest & 0.662 & 0.89 & $0.53,1.50$ \\
\hline Second & 0.005 & 0.37 & $0.18,0.75$ \\
\hline Middle & 0.503 & 0.83 & $0.48,1.44$ \\
\hline Fourth & 0.278 & 0.74 & $0.42,1.28$ \\
\hline Richest & \multicolumn{3}{|c|}{1.00 (Reference) } \\
\hline \multicolumn{4}{|l|}{ Mother's education } \\
\hline None & 0.218 & 1.72 & $0 \cdot 72,4 \cdot 10$ \\
\hline Primary & 0.009 & $2 \cdot 29$ & $1.23,4.26$ \\
\hline Secondary & 0.159 & 1.57 & $0.84,2.94$ \\
\hline High/higher & \multicolumn{3}{|c|}{1.00 (Reference) } \\
\hline \multicolumn{4}{|l|}{ Region } \\
\hline Belgrade & \multicolumn{3}{|c|}{1.00 (Reference) } \\
\hline Vojvodina & 0.002 & 0.48 & $0.30,0.76$ \\
\hline Sumadija and Western Serbia & $<0.001$ & 0.22 & $0.11,0.42$ \\
\hline Southern and Eastern Serbia & $<0.001$ & 0.40 & $0.24,0.65$ \\
\hline \multicolumn{4}{|l|}{ Recent health symptoms } \\
\hline \multicolumn{4}{|l|}{ Child had diarrhoea in last 2 weeks } \\
\hline Yes & & \multicolumn{2}{|c|}{1.00 (Reference) } \\
\hline No & 0.675 & 0.86 & $0.43,1.73$ \\
\hline \multicolumn{4}{|l|}{ Child had cough in last 2 weeks } \\
\hline Yes & & \multicolumn{2}{|c|}{1.00 (Reference) } \\
\hline No & 0.070 & 0.69 & $0.46,1.03$ \\
\hline
\end{tabular}

representative and random sample of children aged 2-5 years and their families, by applying the well-known MICS methodology developed by $\mathrm{UNICEF}^{(9)}$. Results of our study indicated that a lower level of mother's education increased the chance for children's undernutrition. Besides education, ethnicity (being Roma) was associated with higher odds for children's undernutrition, but it seemed that this association was mediated by maternal education and vice versa. It was shown that Roma children had almost double the chance to be undernourished compared with non-Roma children (model 1). This association was mediated by the degree of mother's education. The association between undernutrition and ethnicity disappeared after controlling for mother's education (model 2 ), and only secondary education was a predictor of child undernutrition ( $\mathrm{OR}=1.92 ; 95 \%$ CI 1.00, 3.67). When removing ethnicity from the analysis (model 3), a significant change was noted in the strength of the association between the level of mother's education and undernutrition (mother's primary education $v$. high education: $\mathrm{OR}=2.98 ; 95 \%$ CI 1.50, 5.94; mother's secondary education $v$. high education: $\mathrm{OR}=2 \cdot 02 ; 95 \% \mathrm{CI}$ $1 \cdot 06,3 \cdot 86)$. Having in mind the strong correlation between 
Table 4 Univariate and multivariate logistic regression analyses: associations of socio-economic characteristics with undernutrition among children aged 2-5 years from Roma and non-Roma settlements; UNICEF fourth Multiple Indicator Cluster Survey, Serbia, 2010

\begin{tabular}{|c|c|c|c|c|c|c|}
\hline & \multicolumn{3}{|c|}{ Univariate logistic regression } & \multicolumn{3}{|c|}{ Multivariate logistic regression } \\
\hline & $P$ value & OR & Cl $95 \%$ & $P$ value & OR & $\mathrm{Cl} 95 \%$ \\
\hline \multicolumn{7}{|l|}{ Model 1} \\
\hline \multicolumn{7}{|l|}{ Ethnicity } \\
\hline Non-Roma & \multicolumn{4}{|c|}{1.00 (Reference) } & \multicolumn{2}{|c|}{1.00 (Reference) } \\
\hline Roma & 0.002 & 1.79 & $1.23,2.60$ & 0.005 & 1.79 & $1 \cdot 19,2 \cdot 70$ \\
\hline \multicolumn{7}{|l|}{ Wealth index quintile } \\
\hline Poorest & 0.662 & 0.89 & $0.53,1.50$ & 0.761 & 0.92 & $0.52,1.61$ \\
\hline Second & 0.005 & 0.37 & $0.18,0.75$ & 0.033 & 0.46 & $0.22,0.94$ \\
\hline Middle & 0.503 & 0.83 & $0.48,1.44$ & 0.970 & 0.99 & $0.56,1.75$ \\
\hline Fourth & 0.278 & 0.74 & $0.42,1.28$ & 0.600 & 0.86 & $0.49,1.52$ \\
\hline Richest & \multicolumn{3}{|c|}{1.00 (Reference) } & & \multicolumn{2}{|c|}{1.00 (Reference) } \\
\hline \multicolumn{7}{|l|}{ Region } \\
\hline Belgrade & \multicolumn{4}{|c|}{1.00 (Reference) } & \multicolumn{2}{|c|}{1.00 (Reference) } \\
\hline Vojvodina & 0.002 & 0.48 & $0.30,0.76$ & 0.010 & 0.53 & $0.32,0.86$ \\
\hline Sumadija and Western Serbia & $<0.001$ & 0.22 & $0.11,0.42$ & $<0.001$ & 0.28 & $0.14,0.55$ \\
\hline Southern and Eastern Serbia & $<0.001$ & 0.40 & $0.24,0.65$ & $<0.001$ & 0.39 & $0.23,0.65$ \\
\hline \multicolumn{7}{|l|}{ Model 2} \\
\hline \multicolumn{7}{|l|}{ Ethnicity } \\
\hline Non-Roma & \multicolumn{4}{|c|}{1.00 (Reference) } & \multicolumn{2}{|c|}{1.00 (Reference) } \\
\hline Roma & 0.002 & 1.79 & $1 \cdot 23,2.60$ & 0.162 & 1.54 & $0.84,2.82$ \\
\hline \multicolumn{7}{|l|}{ Wealth index quintile } \\
\hline Poorest & 0.662 & 0.89 & $0.53,1.50$ & 0.456 & 0.79 & $0.42,1.48$ \\
\hline Second & 0.005 & 0.37 & $0.18,0.75$ & 0.013 & 0.39 & $0.19,0.82$ \\
\hline Middle & 0.503 & 0.83 & $0.48,1.44$ & 0.622 & 0.86 & $0.48,1.55$ \\
\hline Fourth & 0.278 & 0.74 & $0.42,1.28$ & 0.400 & 0.78 & $0.44,1.39$ \\
\hline Richest & \multicolumn{4}{|c|}{1.00 (Reference) } & \multicolumn{2}{|c|}{1.00 (Reference) } \\
\hline Region & & & & & & \\
\hline Belgrade & & & ference) & & & erence) \\
\hline Vojvodina & 0.002 & 0.48 & $0.30,0.76$ & 0.012 & 0.54 & $0.33,0.87$ \\
\hline Sumadija and Western Serbia & $<0.001$ & 0.22 & $0.11,0.42$ & $<0.001$ & 0.27 & $0.14,0.55$ \\
\hline Southern and Eastern Serbia & $<0.001$ & 0.40 & $0.24,0.65$ & $<0.001$ & 0.39 & $0.23,0.66$ \\
\hline Mother's education & & & & & & \\
\hline None & 0.218 & 1.72 & $0 \cdot 72,4 \cdot 10$ & 0.456 & 1.55 & $0.49,4.88$ \\
\hline Primary & 0.009 & $2 \cdot 29$ & $1.23,4.26$ & 0.100 & 2.07 & $0.87,4.92$ \\
\hline Secondary & 0.159 & 1.57 & $0.84,2.94$ & 0.050 & 1.92 & $1.00,3.67$ \\
\hline High/higher & & & ference) & & & erence) \\
\hline Model 3 & & & & & & \\
\hline Wealth index quintile & & & & & & \\
\hline Poorest & 0.662 & 0.89 & $0.53,1.50$ & 0.081 & 0.52 & $0.25,1.08$ \\
\hline Second & 0.005 & 0.37 & $0.18,0.75$ & 0.630 & $1 \cdot 16$ & $0.64,2 \cdot 11$ \\
\hline Middle & 0.503 & 0.83 & $0.48,1.44$ & 0.877 & 1.05 & $0.56,1.97$ \\
\hline Fourth & 0.278 & 0.74 & $0.42,1.28$ & 0.292 & 1.40 & $0.75,2.59$ \\
\hline Richest & & & ference) & & & erence) \\
\hline Region & & & & & & \\
\hline Belgrade & & & ference) & & & erence) \\
\hline Vojvodina & 0.002 & 0.48 & $0.30,0.76$ & 0.007 & 0.51 & $0.32,0.84$ \\
\hline Sumadija and Western Serbia & $<0.001$ & 0.22 & $0.11,0.42$ & $<0.001$ & 0.26 & $0.13,0.52$ \\
\hline Southern and Eastern Serbia & $<0.001$ & 0.40 & $0.24,0.65$ & $<0.001$ & 0.40 & $0.24,0.67$ \\
\hline Mother's education & & & & & & \\
\hline None & 0.218 & 1.72 & $0.72,4.10$ & 0.067 & 2.44 & $0.94,6.34$ \\
\hline Primary & 0.009 & $2 \cdot 29$ & $1.23,4.26$ & 0.002 & 2.98 & $1.50,5.94$ \\
\hline Secondary & 0.159 & 1.57 & $0.84,2.94$ & 0.033 & 2.02 & $1.06,3.86$ \\
\hline High/higher & & & ference) & & & erence) \\
\hline
\end{tabular}

education and ethnicity and the fact that ethnicity completely lost its significance after controlling for education and other socio-economic variables in the model, we realized that the role of education is crucial. This observation is understandable because, in general, the Roma population, especially Roma women, is less educated than the non-Roma population ${ }^{(26)}$. It is important to emphasize that the Roma population is the largest disadvantaged population group in Serbia ${ }^{(27-30)}$ and the second largest ethnic group, accounting for 2.05\% (147604) of the total population in Serbia ${ }^{(31)}$. According to the data from a pilot census conducted among the Roma population, their educational status is very low: just $30.4 \%$ of the Roma population completed primary school (adults older than 15 years), while the proportion of those with high or higher education is $7.41 \%{ }^{(26)}$. In our sample, almost $70 \%$ of Roma women completed primary school, which might be a consequence of the younger age of women in our sample as compared 
with those covered by the pilot census. This observation indicates that new generations of Roma women are attending school more frequently than their ancestors.

Another possible explanation for the association and interplay between mother's education, ethnicity and undernutrition of children is the fact that Roma women and men are initiating intimate partner relationships in their early age, which are often ending in pregnancy. According to the pilot census conducted in Roma households, more than one-third of Roma women (38\%) have their first child before the age of 18 years, and $10 \%$ of them even before the age of 16 years ${ }^{(26)}$. Generally speaking, undereducated mothers (those who completed just primary school) are usually not able to understand birth control options ${ }^{(32,33)}$, so they get pregnant and deliver the baby very early as teenagers, before completing secondary school. Most often they do not get back to school due to the obligations related to motherhood. It is a pity that the data set we worked on did not provide information on mother's age, so we cannot firmly support these assumptions. Still, our assumptions are based on the fact that teenage pregnancies are associated with low birth weight, which leads to undernutrition further in childhood ${ }^{(34-38)}$.

Surprisingly, we found that there was no strong relationship between wealth index and children's undernutrition, except the finding that poor children (second quintile) had fewer chances to be undernourished in comparison to the richest (fifth quintile). A possible explanation might be that food and nutrition are a priority for low-income families: 'basic needs first', according to Maslow's hierarchy of human needs ${ }^{(39)}$. It could also be due to natural selection which is present from early childhood, so that children in low-income families who are less capable of living or undernourished simply do not survive ${ }^{(40,41)}$.

Children living in all regions other than Belgrade had less chance to be undernourished, independently of other variables. Unfavourable environmental factors such as air pollution, noise and high density of population in Belgrade might be responsible for adverse effects on the nutritional status of children. Except environment, a possible explanation could be a great migration (from rural areas to Belgrade) which is mostly caused by unemployment due to the lack of qualifications and low level of education. In Belgrade, people have very low income and disproportionately high rents, so they can barely feed the family. With the need to earn more, they are forced to have more than one job or to spend many hours at work, and almost to neglect children and their developmental needs. During their parents' working hours, most children spend time at day-care centres. The Statistical Office of the Republic of Serbia has reported that Belgrade is the region with the highest percentage of day-care centre attendance and also the highest percentage of children who spend more than $9 \mathrm{~h} / \mathrm{d}$ there, in comparison to other Serbian regions ${ }^{(42)}$. Although daycare centre attendance could serve as a protective factor against malnutrition ${ }^{(43,44)}$, a study conducted among Dutch toddlers (1-3 years old), both at childcare and at home, showed that children consumed more or less equal amounts of energy at home and childcare ${ }^{(45)}$. In Belgrade, we have quite the opposite situation. The duration of children's stay in day-care centres can be very variable. Children can stay at day-care centres for between 6 and $12 \mathrm{~h} / \mathrm{d}$. During that time they are supposed to receive a certain number of meals, according to the official nutritional recommendations for their age. While we can only speculate about children's compliance to the food intake in day-care centres, the above-mentioned patterns of parental long working hours and less time spent at home are usually associated with a lack of time to prepare meals. Therefore, parents most often rely only on the nutrition children receive at day-care centres, while they provide not more than some snacks at home. These results have been confirmed in one study conducted in North America, where attending day-care centres did not show any favourable effects on child nutritional status ${ }^{(46)}$.

The present study has certain limitations. The crosssectional study design used provides just a 'snapshot' of the prevalence rate of undernourished children in Serbia and the socio-economic characteristics associated with it. Future longitudinal studies can solve this disadvantage. Also, the data were self-reported, so there is a possibility that some answers were not credible.

On the other hand, using a well-acknowledged method (MICS4) and data based on a nationally representative sample ensure the relevance of the obtained results and their use for future planning and generalization. Despite the limitations, the present study is among the first in Serbia which examines the role of mother's education in child undernutrition in Serbia. Therefore, it can serve as a benchmark for further studies that will analyse factors associated with children's nutritional status.

The study results indicate that one of the main determinants of undernutrition among children in Serbia is rooted in mothers' education. This result has been confirmed in other countries too ${ }^{(12-14,19,34-38)}$. This finding is independent of ethnicity, area of living and the wealth index, with the exception of Belgrade, the capital of Serbia, where child undernutrition is more frequent than in the other Serbian regions, and surprisingly it is least in the second poorest layer of the wealth index. It implies that decision makers and public health authorities need to initiate actions to enhance women's educational promotion and to address social determinants to achieve optimal health outcomes as highlighted by the Commission on the Social Determinants of Health ${ }^{(47)}$.

\section{Acknowledgements}

Acknowledgements: The authors would like to thank UNICEF for the access to the MICS4 database. Financial support: This work was supported by the Ministry of 
Science and Technological Development of Serbia (project number 175025). Conflict of interest: None. Authorship: All authors took part in this research from the very early beginning until the final approval of the manuscript. Z.S. contributed to concept and design, acquisition of data, analysis and interpretation of data, drafting the article and final approval of the manuscript. B.D. contributed to concept and design, analysis of data, revising the article draft critically for important intellectual content and final approval of the manuscript. U.L. contributed to concept and design, revising the article draft critically for important intellectual content and final approval of the manuscript. V.B.-M. contributed to concept and design, revising the article draft critically for important intellectual content and final approval of the manuscript. All authors agree to take responsibilities for all aspects of the work in ensuring that questions related to the accuracy or integrity of any part of the work are appropriately investigated and resolved. Also, all authors accept responsibility for the paper as published. Ethics of buman subject participation: After receiving information on the study and before completing the questionnaire, all participants gave an informed consent in compliance with the Helsinki Declaration.

\section{References}

1. Lim SS, Vos T, Flaxman AD et al. (2012) A comparative risk assessment of burden of disease and injury attributable to 67 risk factors and risk factor clusters in 21 regions 1990-2010: a systematic analysis for the Global Burden of Disease Study 2010. Lancet 380, 2224-2260.

2. Black RE, Victora CG, Walker SP et al. (2013) Maternal and child undernutrition and overweight in low-income and middle-income countries. Lancet 382, 427-451.

3. Dewey KG \& Begum K (2011) Long-term consequences of stunting in early life. Matern Child Nutr 7, Suppl. 3, 5-18.

4. UNICEF, World Health Organization \& The World Bank (2012) UNICEF-WHO-World Bank Joint Child Malnutrition Estimates. New York/Geneva/Washington, DC: UNICEF/ WHO/World Bank; available at http://www.who.int/ nutgrowthdb/jme_unicef_who_wb.pdf

5. UNICEF, WHO, The World Bank et al. (2011) Levels and Trends in Child Mortality: Report 2011, p. 19. New York: Oxford University Press.

6. Caulfield LE, Richard SA, Rivera JA et al. (2006) Stunting, wasting and micronutrient deficiency disorders. In Disease Control Priorities in Developing Countries, pp. 551-567 [DT Jamison, JG Breman, AR Measham et al., editors]. New York: Oxford University Press.

7. Martorell R \& Zongrone A (2012) Intergenerational influences on child growth and undernutrition. Paediatr Perinat Epidemiol 26, Suppl. 1, 302-314.

8. Statistical Office of the Republic of Serbia \& Strategic Marketing Research Agency (2006) Republic of Serbia Multiple Indicator Cluster Survey 2005, Final Report. Belgrade: Statistical Office of the Republic of Serbia and Strategic Marketing Research Agency.

9. Republic Institute for Statistics (2012) Multiple Indicator Cluster Survey in the Republic of Serbia, 2010. Final Report. Belgrade: Republic Institute of Statistics.

10. Marmot $\mathrm{M}$, Allen $\mathrm{J}$, Bell $\mathrm{R}$ et al.; Consortium for the European Review of Social Determinants of Health and the
Health Divide (2012) WHO European review of social determinants of health and the health divide. Lancet $\mathbf{3 8 0}$, 1011-1029.

11. Victora CG, Adair L, Fall C et al.; Maternal and Child Undernutrition Study Group (2008) Maternal and child undernutrition: consequences for adult health and human capital. Lancet 371, 340-357.

12. Mohammad K, Kassab M, Gamble J et al. (2014) Factors associated with birth weight inequalities in Jordan. Int Nurs Rev 61, 435-440.

13. Keino S, Plasqui G, Ettyang G et al. (2014) Determinants of stunting and overweight among young children and adolescents in sub-Saharan Africa. Food Nutr Bull 35, 167-178.

14. Nguyen HT, Eriksson B, Petzold M et al. (2013) Factors associated with physical growth of children during the first two years of life in rural and urban areas of Vietnam. BMC Pediatr 13, 149.

15. Black RE, Allen LH, Bhutta ZA et al.; Maternal and Child Undernutrition Study Group (2008) Maternal and child undernutrition: global and regional exposures and health consequences. Lancet 371, 243-260.

16. Chopra M (2003) Risk factors for undernutrition of young children in a rural area of South Africa. Public Health Nutr 6, 645-652.

17. Hien NN \& Kam S (2008) Nutritional status and the characteristics related to malnutrition in children under five years of age in Nghean, Vietnam. J Prev Med Public Health 41, 232-240.

18. Hong R, Banta JE \& Betancourt JA (2006) Relationship between household wealth inequality and chronic childhood under-nutrition in Bangladesh. Int $J$ Equity Health 5, 15.

19. Tornaritis MJ, Philippou E, Hadjigeorgiou C et al. (2014) A study of the dietary intake of Cypriot children and adolescents aged 6-18 years and the association of mother's educational status and children's weight status on adherence to nutritional recommendations. BMC Public Health 14, 13 .

20. Tette EM, Sifah EK \& Nartey ET (2015) Factors affecting malnutrition in children and the uptake of interventions to prevent the condition. BMC Pediatr 15, 189.

21. Fekadu Y, Mesfin A, Haile D et al. (2015) Factors associated with nutritional status of infants and young children in Somali Region, Ethiopia: a cross-sectional study. BMC Public Health 15, 846

22. Kinyoki DK, Berkley JA, Moloney GM et al. (2015) Predictors of the risk of malnutrition among children under the age of 5 years in Somalia. Public Health Nutr 18, 3125-3133.

23. Rutstein SO \& Johnson K (2004) The DHS Wealth Index. DHS Comparative Reports no. 6. Calverton, MD: ORC Macro; available at http://www.measuredhs.com/pubs/pdf/ CR6/CR6.pdf

24. WHO Multicentre Growth Reference Study Group (2006) WHO Child Growth Standards: Length/Height-forAge, Weight-for-Age, Weight-for-Length, Weight-for-Height and Body Mass Index-for-Age: Methods and Development. Geneva: WHO.

25. World Health Organization (1995) Physical Status: The Use and Interpretation of Anthropometry. Report of a WHO Expert Committee. WHO Technical Report Series no. 854. Geneva: WHO.

26. Vukmirovic D, Djordjevic LJ \& Lakcevic S (editors) (2010) Roma in Census. Pilot Census of Population, Households and Dwellings from 1 to 15 November 2009. Belgrade: Republic Institute for Statistics.

27. Semba RD, de Pee S, Sun K et al. (2008) Effect of parental formal education on risk of child stunting in Indonesia and Bangladesh: a cross sectional study. Lancet 371, 322-328. 
28. Stojanovski K, McWeeney G, Emiroglu N et al. (2012) Risk factors for low vaccination coverage among Roma children in disadvantaged settlements in Belgrade, Serbia. Vaccine 30, 5459-5463

29. Hajioff S \& McKee M (2000) The health of the Roma people: a review of the published literature. J Epidemiol Community Health 54, 864-869.

30. Bobak M, Dejmek J, Solansky I et al. (2005) Unfavourable birth outcomes of the Roma women in the Czech Republic and the potential explanations: a population-based study. BMC Public Health 5, 106.

31. Republic Institute for Statistics (2012) Census 2011 in the Republic Serbia. Book 1: Ethnicity. http://media.popis2011. stat.rs/2013/publikacije/Saopstenje29novembarKnjiga1.pdf (accessed November 2014).

32. El-Ibiary SY \& Youmans SL (2007) Health literacy and contraception: a readability evaluation of contraceptive instructions for condoms, spermicides and emergency contraception in the USA. Eur J Contracept Reprod Health Care 12, 58-62.

33. Ishikawa H, Yano E, Fujimori S et al. (2009) Patient health literacy and patient-physician information exchange during a visit. Fam Pract 26, 517-523.

34. World Health Organization (2014) Adolescent pregnancy fact sheet. http://www.who.int/mediacentre/factsheets/ fs364/en/ (accessed November 2014).

35. Santos GH, Martins G \& Sousa S (2008) Teenage pregnancy and factors associated with low birth weight. Rev Bras Ginecol Obstet 30, 224-231.

36. Guimarães AM, Bettiol H, Souza Ld et al. (2013) Is adolescent pregnancy a risk factor for low birth weight? Rev Saude Publica 47, 11-19.

37. Chen XK, Wen SW, Fleming N et al. (2007) Teenage pregnancy and adverse birth outcomes: a large population based retrospective cohort study. Int J Epidemiol 36, 368-373.
38. Harville EW, Madkour AS \& Xie Y (2012) Predictors of birth weight and gestational age among adolescents. Am J Epidemiol 176, Suppl., S150-S163.

39. Maslow AH (1943) A theory of human motivation. Psychol Rev 50, 370-396.

40. Janevic T, Petrovic O, Bjelic I et al. (2010) Risk factors for childhood undernutrition in Roma settlements in Serbia. BMC Public Health 10, 509.

41. Sepkowitz KA (2006) Health of the world's Roma population. Lancet 367, 1707-1708.

42. Statistical Office of the Republic of Serbia (2013) Announcement No. 104, Year LXIII, Statistical Office of the Republic of Serbia. http://webrzs.stat.gov.rs/WebSite/repository/documents/00/00/99/66/dd20042013.pdf (accessed May 2015).

43. Nakahara S, Poudel KC, Lopchan M et al. (2010) Differential effects of out-of-home day care in improving child nutrition and augmenting maternal income among those with and without childcare support: a prospective before-after comparison study in Pokhara, Nepal. Health Policy 97, 16-25.

44. Silva EM, Miranda CT, Puccini RF et al. (2000) Day care centres as an institution for health promotion among needy children: an analytical study in São Paulo, Brazil. Public Health 114, 385-388.

45. Gubbels JS, Raaijmakers LG, Gerards SM et al. (2014) Dietary intake by Dutch 1- to 3-year-old children at childcare and at home. Nutrients 6, 304-318.

46. Bruening KS, Gilbride JA, Passannante MR et al. (1999) Dietary intake and health outcomes among young children attending 2 urban day-care centers. J Am Diet Assoc 99, 1529-1535.

47. World Health Organization (2008) Closing the Gap in a Generation: Health Equity through Action on the Social Determinants of Health. Geneva: WHO. 